\title{
Panopto: the Potential Benefits for Disabled Students
}

\author{
Clifton Kandler, Melanie Thorley \\ University of Greenwich
}

This paper sets out to review the recent Panopto (lecture capturing) trial undertaken at University of Greenwich. We discuss the scope and findings of the trial. The universal design for learning (UDL) concept is briefly addressed to demonstrate how universal design can (even though the emphasis is on disabled students ${ }^{1}$ ) benefit a great many students, thus enabling the university to comply with the Equality Act 2010 aspect of anticipatory measures. In addition to the potential advantages and disadvantages for future disabled students who may not be in receipt of the Disabled Students' Allowances (DSA), we also suggest potential institutional benefits and how different cohorts of non-traditional students may benefit from the technology.

\section{Why Panopto?}

Panopto was chosen for the trial following extensive research by teams within Information and Library Services (ILS) and the Educational Development Unit (EDU), taking into account previous knowledge and experience of Echo 360 . Hardware-based systems such as Echo 360 were quickly ruled out on the basis of cost and flexibility. Panopto was therefore selected for the following reasons:

- the ability to use the system on personal computers, laptops, Macs, tablets and mobile phones;

- the ability to search videos for key words spoken by the presenter or appearing on PowerPoint slides;

- the ability to integrate with the University's virtual learning environment (VLE);

- the ability to live-stream presentations;

- ease of use;

- it is the most widely adopted lecture-capturing system within UK higher education;

- its compatibility with a number of assistive software technologies.

In addition, the system was developed from a project at Carnegie Mellon University and, at an early stage, Eric Burns, Chief Product Officer, identified its importance for meeting the needs of disabled students: "One of the original applications of our video platform was to bring Camegie Mellon University lectures to physically disabled students who couldn't attend class." (Schafhause, 2013).

\section{The Trial: Scope and Findings}

The group designed the trial to take place in semester one of the 2014/15 academic year. Over forty academics across all faculties initially volunteered to take part in the trial. Those who volunteered to take part but who did not actually participate reported that this was largely because of the limited time available to plan for the inclusion of the system in teaching activities and doubts about the availability of the system in the long term.

\footnotetext{
1 'disabled students' covers physical disabilities, the autistic and dyslexia spectrums, long-term health conditions and mental health difficulties.
} 
Feedback from those who took part in the trial was very positive. First-and final-year student committees in the Department of Computing and Information Systems requested all lectures to be made available via Panopto. The Student Union also used the system and consulted with students; They reported that students would like all of their lectures recorded. However, the legal and policy aspects of the trial were areas identified as requiring further investigation and discussion at a senior level within the University.

\section{Universal Design for Learning: Potential Benefits for Disabled Students}

The concept of UDL is not a new one ${ }^{2}$ and yet many lecturers and students are unaware of how the seven principles can benefit the majority. Whilst UDL began life as an architectural and design concept, the principles can be applied to technology. This is exemplified in Principle One - Equitable Use: the design is useful for and marketable to people with diverse abilities $^{3}$. As Sheryl Burgstahler from the Wyoming Institute for Disabilities (WIND) states, "When UDL principles are applied, products and environments meet the needs of potential users with a wide variety of characteristics. Disability is just one of many characteristics that an individual might possess."”

Several authors (Brogan, 2009; Williams \& Fardon, 2005) have identified lecture capture as a means of implementing UD principles, the main UD benefit being flexibility of access.

Lecture capturing facilities may be one method by which the University can adhere to the Equality Act 2010 and thus avoid discrimination. The purpose of the duty is to ensure that disabled students can access their education on a par with their peers (Slater et al, 2015).

Recorded lectures can provide valuable (and valued) revision materials for students, as well as being particularly useful for students who may find difficulty comprehending a lecture fully at the time of delivery (Karnard $2013^{5}$; Owston et al, 201166). Some disabled students require notetaking support for their lectures and seminars - for example, deaf and hard-of-hearing students who cannot physically hear the lecture ${ }^{7}$ or physically-disabled students who cannot maintain notetaking at a sufficiently fast pace ${ }^{8}$ to keep up.

Whilst Panopto is not a universal remedy, there have been suggestions from as far back as 2007 (Hughes and Robinson) that lecture-capturing may reduce the need for notetakers in lectures. A study from Canada confirmed that $81 \%$ of students who had identified a need for 'accommodations' (reasonable adjustments in the UK) reported that lecture-capturing was helpful (Vajoczki et al, 2010). A number of the disabled students in this study suggested that lecture-capturing might replace their need for notetakers. This is timely, owing to the imminent cuts to DSAs which currently fund the majority of notetakers within UK higher

\footnotetext{
2 http://www.ncsu.edu/www/ncsu/design/sod5/cud/about ud/udprinciplestext.htm

${ }^{3}$ http://www.ncsu.edu/www/ncsu/design/sod5/cud/about ud/udprinciplestext.htm

4 http://www.uwyo.edu/wind/ files/docs/resources/ud review.pdf

${ }^{5}$ http://eprints.Ise.ac.uk/50929/1/Karnad_Student_use_recorded_2013_author.pdf

${ }^{6} \mathrm{http}: / /$ www.sciencedirect.com/science/article/pii/S1096751611000418

7 http://eric.ed.gov/?id=ED437777 Notetaking for Deaf and Hard of Hearing Students 1997

8 http://cjo.sagepub.com/content/67/3/162.full.pdf+html Accommodation Needs and Student

Environment Fit in Upper Secondary Schools for Students with Severe Phy sical Disabilities 2000

Compass: Journal of Learning and Teaching, Vol 8, No 12, 2016
} 
education (Willetts, 2014). The potential benefits for students with a disability and/or specific learning difficulty are numerous and are presented in the table below.

\section{A synopsis of the potential advantages and disadvantages of Panopto for disabled students:}

\begin{tabular}{|l|l|}
\hline Potential Advantages & Potential Disadvantages \\
\hline 24-hour access & Cognitive overload/saturation \\
\hline Illness or hospitalisation & Technical failure \\
\hline Substantial bereavement & $\begin{array}{l}\text { May discourage students from attending } \\
\text { lectures }\end{array}$ \\
\hline Less reliance on in-class support staff & Unhelpful and/or technophobic teaching staff \\
\hline $\begin{array}{l}\text { Fonts, screen colours and audio can be } \\
\text { altered }\end{array}$ & $\begin{array}{l}\text { Non-engagement, owing to the technical } \\
\text { knowledge and understanding required }\end{array}$ \\
\hline $\begin{array}{l}\text { Visual instruction for deaf and hard-of- } \\
\text { hearing learners }\end{array}$ & Costly equipment may be required at home \\
\hline $\begin{array}{l}\text { Audio instruction for blind or visually- } \\
\text { impaired students }\end{array}$ & \\
\hline Enhanced student experience & \\
\hline Can be used on mobile devices & \\
\hline
\end{tabular}

However, lecture capture is not a panacea, as accessing lecture content is just one aspect of a university education for a disabled student (Gibson, 2015).

\section{Potential institutional benefits:}

- Recruitment-65+ universities use Panopto in the UK. Prospective students' choice of university may well depend on the availability of lecture-capturing services.

- Retention: flexible approaches to accessing lectures and/or seminars may enable students at risk of leaving their degree early to stay the course. Two disabled students in the Vajoczki et al study reported that, owing to deteriorating medical conditions, they would not have completed their degrees without such assistance.

- The cuts in the Disabled Students' Allowances (DSAs) will revoke much of the support which is currently available and lecture capture systems constitute one means by which universities may be able to fill this gap.

- Enables the university to practice reasonable and anticipatory adjustments.

- Lecture capturing may also assist other cohorts of non-traditional (widening participation) students, such as students who have English as an additional language; students who are the first in their family to go to university and may not have had access to the terminology/vocabulary used in higher education; students who are caring for a disabled relative; students with a low socioeconomic status, who may struggle with travel costs to and from the university.

\section{Conclusion}

Following the trial, the University has adopted Panopto on an 'opt-in' basis, meaning that, whilst its use is encouraged, it is not compulsory for staff to provide recordings of lectures. The reception by both staff and students of the system continues to be very positive. The 


\section{Technology Review}

team leading the system's implementation is now focusing on raising academic staff awareness of its availability and potential; there is also particular focus on ensuring that the University's disability team is aware of the system's potential to support students with a wide range of disabilities. The *Accessibility Project will continue to inform disabled students in their outreach work of the benefits of lecture capture to the disabled students they work with.

This review confirms in its exploration of lecture capturing that there are significant immediate and subsequent benefits to students, both disabled and, more widely, nontraditional, as well as to their higher education institutions. At a time when DSA.s are threatened, universities may well find it worthwhile to address such potential disadvantages as are identified here to capitalise upon the undeniable benefits of these systems.

\section{Reference list}

Brogan, P. (2009) Echo360: Lecture capture solutions for students with disabilities. Available at: http://www.automaticsync.com/captionsync/wp-content/uploads/AccessibleLectures11.pdf (Accessed: 09 January 2016).

Gibson, S. (2015) 'When rights are not enough: What is? Moving towards new pedagogy for inclusive education within UK universities.' International Journal of Inclusive Education, 19(8).

Hughes, G. and Robinson, P. (2007) 'Photonote Evaluation: Aiding Students with Disabilities in a Lecture Environment.' International ACM Conference, October 15-17, Arizona. New York: ACM Press.

Karnard, A. (2013) 'A report reviewing recent research into the use of lecture capture technology in higher education'. Available at:

http://eprints.Ise.ac.uk/50929/1/Karnad Student use recorded 2013 author.pdf

(Accessed: 10 January 2016).

Owston, H., Lupshenyuk, D. and Wideman, H. (2011) 'Lecture capture in large undergraduate classes: student perceptions and academic performance'. Available at: http://www.sciencedirect.com/science/article/pii/S1096751611000418 (Accessed: 10 January 2016).

Schaffhause, D. (2013) 'Panopto Updates Lecture Capture Suite with New Accessibility Tools, Security Enhancements.' The Journal. Available at:

https://thejournal.com/articles/2013/10/17/panopto-4.5-video-tools-enhance-accessibilityusability-security.aspx?=THE21 (Accessed: 12 October 2015).

Slater, R., Pearson, V.K., Warren, J.P. and Forbes, T. (2015) 'Institutional change for improving accessibility in the design and delivery of distance learning - the role of faculty accessibility specialists at the Open University.' Open Learning: The Journal of Open, Distance and e-Learning, 30(1).

Vajoczki, S., Watt, S., Marquis, N. and Holshausen, K. (2010) Podcasts: Are they an effective tool to enhance student learning? A case study from McMaster University, Hamilton Canada, Journal of Educational Multimedia and Hypermedia, 19 (3)

Willetts, D. (2007) Higher education: student support: changes to Disabled Students' Allowances (DSA). Available at: https://www.gov.uk/government/speeches/higher-education- 


\section{Technology Review}

student-support-changes-to-disabled-students-allowances-dsa (Accessed: 19 October 2015).

Williams, J. and Fardon, M. (2005) 'On-demand internet-transmitted lecture recordings:

Attempting to enhance and support the lecture experience.' Proceedings of the Association for Learning Technology Conference: Exploring the frontiers of e-learning: borders, outposts and migration. 153-161. Manchester, England. Available at: http://

www.lectopia.com.au/misc/WilliamsFardon ALT-C 2005.pdf (Accessed: 09 January 2016). 